\title{
Application of Self Care Orem's theory Guideline on elderly Suffering from Urinary Diversion
}

\author{
*Amal I. Fouad \& **Safia Ali Belal \\ *Lecturer of geriatric health nursing/faculty of nursing/fayoum university/Egypt \\ **Medical surgical nursing, Ain Shams University/Egypt
}

\begin{abstract}
:
Background: Urinary diversion is indicated for the management of bladder carcinoma because radical cystectomy remains the mainstay of treatment for this type of cancer. The patient facing urinary diversion now need appropriate knowledge and self care practices to prevent surgical complications.
\end{abstract}

Aim: evaluate the effect of application of self care Orem theory guideline on elderly suffering from urinary diversion.

Design: A quasi-experimental research design was used in this study.

Setting: urologic department, National Cancer Institute, Cairo University.

Sample: A purposive sample used in this study, it composed of 50 urinary diversion patients according to certain criteria which divided randomly into two groups control group and study group.

Tools: Three tools used in this study, first: An Arabic interviewing questionnaire to assess, Socio-demographic data of urinary diversion patients, second: medical record analysis to collect patient's clinical data as past and present history. Third: Orem's self-care guideline checklists to assess patients' ability to perform skills related to their practices.

Results: the results shows that mean age of the study group was 63.5+7.6. Also, there were no statistically significant differences between the mean and standard deviation regarding self-care practices in both study and control groups pre-application of self care guidelines at $P>0.05$. There were highly statistically significant difference between study group and control group regarding their knowledge about urinary diversion and stoma care at post and follow up of application guidelines where $p<0.001$. Also, there was highly statistically significant difference between them at post and follow up the application of self care guidelines where $p$ value < 0.001 .

Conclusion: The application self-care guidelines had statistically significant improvement on knowledge and self care practices for patients with urinary diversion pre, post and follow up program implementation phases as well as compared to control group.

Recommendation: Periodic implementation of the designed self care guideline for cancer's patients in the clinic, out patients and hospitals when the patients admitted to provide them with the necessary and required knowledge and self care practices about their disease is mandatory.

Keywords: Self-care/ urinary diversion/ elderly/ Patient education

\section{Introduction}

Urinary diversion is a procedure used to give urine a new method to leave the body. It is necessary when the bladder has been removed because of cancerous tumors or other conditions. It is also performed when a patient's urinary bladder stops working but is still in the body. Urinary diversion often ends with a patient's urine exiting the body through the abdominal wall (Shariat \& Milowsky, 2010). According to (Leveridge et al., 2015) stated that there are common types of urinary diversions, first: is Ileal Conduit that allows urine to drain through a stoma into an external bag affixed to the abdomen. This is the most common of the diversions used by most general urologists. Second: is continent diversions continent urinary diversion which made of harvested intestine formed into an internal pouch which allows urine to collect and then will be drained using a catheter inserted into a stoma located on the abdomen or in the navel. Third: is neo-bladder urinary diversion that uses harvested intestine to form an internal pouch which allows urine to collected and be voided normally though the urethra.

Each year the American Cancer Society estimates the numbers of new cancer cases and deaths that will occur in the United States in the current year and compiles the most recent data on cancer incidence, mortality. Incidence data were collected by the National Cancer Institute (Surveillance, Epidemiology, and End Results [SEER] Program) Mortality data were collected by the National Center for Health Statistics. A total of $1,658,370$ new cancer cases and 589,430 cancer deaths are projected to occur in the United States in 2015 (SEER Cancer Statistics Factsheets, 2016). As know cancer is the fearful, stressful, and life threatening illness. As well consider as a significant serious extensive health problem in the developing countries. Cancer is 
not one disease; it is a group of more than 100 different and distinctive diseases which can leads to serious complication and death (Ferlay et al., 2015). The indications for urinary diversion include bladder cancer, hostile neurogenic bladder, refractory interstitial or radiation cystitis, and congenital anomalies of the lower urinary tract. Bladder cancer is the most common indication for continent urinary diversion. These malignancies account for about $3 \%$ of all cancer deaths (Black \& Matassarin, 2015).

Superficial bladder tumors are managed by transurethral resection or laser ablation with or without intravesical chemotherapy, but more invasive tumors require radical cystectomy and urinary diversion. Neurogenic bladder dysfunction occurs when trauma, infection, or disease alters neurological control of the lower urinary tract. The neurogenic bladder creates two primary problems from the urological perspective: voiding dysfunction (urinary incontinence or retention) and upper urinary tract distress, which is characterized by ureterohydronephrosis, vesicoureteral reflux, febrile urinary tract infections, and renal insufficiency or failure ( Patel et al., 2015). Removal of the bladder (cystectomy) necessitates reconstruction of the lower urinary tract. Bladder cancer is the most common reason for cystectomy. However, the same principles apply to patients who undergo pelvic exenteration for other malignancies or who require cystectomy for non-malignant conditions, such as birth defects, trauma, or neurologic disorders (Siegel et al., 2015). The available reconstructive options after cystectomy, the criteria for selection of the most appropriate procedure, and the outcomes and complications associated with the different urinary diversions (Hautmann et al., 2013)

Ureterosigmoidostomy was the first widely used surgical technique for urinary diversion, providing an effective diversion that relied upon the anal sphincter for continence. However, deterioration of renal function over time, metabolic complications, and the increased risk for the development of secondary malignancies limited its usefulness. Subsequent surgical advances in reconstructive techniques have led to major improvements in both functional outcomes and quality of life (Shabsigh et al., 2011). According to the International Declaration of urinary diversion Patient Rights, the patient has the right to receive specialized nursing care in the pre and post surgical period, both at the hospital and in their own communities Several factors influence the patient's self-care, as well as the compliance and motivation toward treatment and proposed interventions. Knowing them is essential in order to understand the challenges of the care process in urinary diversion therapy Garde et al., 2015).

An effective way to promote nursing care is through applying the Self-Care Theory, respecting its essential aspects. By doing so, health care becomes directed to the patient's needs, and approaches the holistic aspects of care. In a simplified manner, self-care can be considered as the individual's capacity to perform all activities necessary to live and survive. Among these are the physical, psychological and spiritual needs (Schiffmann et al., 2014). In studies were motivated to apply the theoretical knowledge learned to the health care practices. Hence, it searched for the Orem's Theory, because it contains elements that are deemed essential for providing nursing care to the urinary diversion patient, and the home care strategy, because it represents a self care guideline for the patient (Orem, 1985). Orem's general theory is comprised of three interrelated theory: theory of self-care; theory of self-care deficit; and theory of nursing systems. The theories are linked by presuppositions or assumptions. The theme of the self-care theory is that the individuals have the ability to care for themselves and their dependents. In the self care deficit theory, which Orem considers the care of her general theory, the central theme is that there are times when limitations occur in an individual's ability for self-care. These limitations, or therapeutic self-care demands, that establish the need for nursing. Nursing systems is Orem's third theory. It is theory that defines a person's need for nursing. The nurse determines that a deficit exists between the abilities and demands placed on a patient and together with the patient develops a plan of care to meet the patient's need (Orem, 1985).

Patient education about bladder management after urinary diversion begins before surgery and is restarted as soon as possible after surgery. While education focuses on the patient, family members and other care providers are included, whenever feasible (Gore \& Litwin, 2012). The pre-operative include guidelines related to planned surgical procedure, the impact of an ostomy on the patient's life, and the basics of ostomy management; sexual counseling; and stoma site selection .Post-operative instruction include teaching the patient the necessary skills to enable him/her to manage the stoma independently (Nishikawa et al., 2014).Any educational intervention can change patients' outcomes including knowledge, skills, attitudes, behaviors, condition or status, resulting from their involvement in a program or service. The changes may be positive or negative, intentional or unintentional and may be short-term, intermediate-term or long-term. Also, end results include quality of life as well as mortality. Outcomes include measures of health improvements in an individual patient, community, or population (Leow et al., 2015).

\section{Significant of the Study:}

In Egypt, it provide the expected numbers of new cancer cases and deaths in 2015, as well as a comprehensive overview of cancer incidence, mortality, and trends using the most current population-based data. It estimate the age group of 55years and above it was found that in Egypt $21.8 \%$ among standardized rate 
per 100.000 diagnosed with cancer bladder and 13.1 cancer deaths. Also, they found that Egypt represent the $13^{\text {th }}$ level around the world of cancer incidence and $10^{\text {th }}$ level in cancer mortality (Ferlay et al., 2015). According to the Annual Statistics Of The National Cancer Institute (2015) the number of patients with bladder cancer requiring radical cystectomy and urinary diversion accompanied with uro-stomy are approximately around 4000 patients. Universal self-care for any patient with disability requisites are associated with life processes, which required maintain for the integrity of human structure and functioning. With application of Orem's theory will identify these requisites, or in different way the patient's activities of daily living.

\section{Aim of the study \\ The study was conducted to evaluate the effect of application of self care Orem theory guideline on elderly suffering from urinary diversion through the following: \\ 1- Assessing levels of knowledge and self-care practical skills for patients with urinary diversion. \\ 2- Developing and implementing educational guideline for patients based on needs assessment. \\ 3- Evaluating the effect of application of self-care guideline on patients' outcome.}

\section{Research Hypothesis:}

Application of self care guideline will have a positive effect on knowledge and practical skills for elderly patients suffering from urinary diversion.

\section{Subjects and methods}

\section{Research design:}

Quasi-experimental research design was utilized to achieve the aim of the study. Setting:

This study was conducted at urologic department, in patients and outpatient clinic in National Cancer Institute, Cairo University. This is a governmental hospital specialized in treatment of cancer patients in Cairo and its build since 1969. The majority of Egyptian cancer' patients treated there.

\section{Sampling:}

A purposive sample of 50 patients they represent about $2 \%$ from the total attending the institute in the period of May to October 2015. the patients have been selected according to the following criteria: (age 55 years and above, from both sex, with bladder cancer requiring radical cystectomy accompanied with urinary diversion were selected, with different educational levels, or fully oriented, patient with uro-stomy and its types, no metastases occur; all of them did not exposed for any educational or learning experience before and they agreed to participate in the study). The study subject was divided into two groups: study group who had the self-care guidelines and control group who had only the routine care. the sample size was determined statistically by power analysis considering the total number of patients who had uro-stomy. The researcher consider type one error with significant level $\alpha=95 \%$, and type 11 error by power test $\beta=90 \%$. The exclusion criteria includes all patient did not agree to participate in the study, patient with mental disorder, patients with chronic condition and metastasizes.

\section{Tools of Data Collection:}

A. An interviewing questionnaire: It was developed by the researcher based on the related literature in addition to the patients medical records to collect data about the following :

1) Socio-demographic sheet: which included questions about patient age, gender, level of education, marital status, income, occupation, place of residence, and it was open ended and closed questions.

2) Questions to assess patients knowledge about radical cystectomy and uro-stomy.

A scoring system for elderly patients knowledge was done as follows, each question had a group of answer points, each correct, complete answer scored had two marks which one mark for an incomplete answer and zero for don't know or incorrect answer. The total score for all questions related to knowledge was 78 marks which represents $100 \%$.

\section{The knowledge scores were categorized into two levels as follows:}

- satisfactory: more than or equal to $60 \%$ of the total score (more than or equal to 47 mark)

- unsatisfactory: less than $60 \%$ of the total score $(<47$ mark).

B. Clinical data sheet: It was developed by the researcher based on the recent and related literature and it was used to collect patient's clinical data as past and present history from medical records.

C. Orem's self-care practices checklists: it was adopted by the researcher to assess patients' ability to perform skills related to self-care which are important to prevent complications as urostomy observation, uro-stomy care, care of peri-stomal skin, changing pouching system, empting the pouch, change the flang, and follow-up (Orem, 1985).

The scoring system used for the self-reported practices questionnaire form was done as follows, each answer scored one mark for (Yes) and zero for (No). Total score of self -reported practices had been 40 marks, 
which represent $100 \%$. Final self-reported practices will be considered satisfactory level if the percent score will be equal to or more than 24 points ( $60 \%$ or more) and unsatisfactory level if less than 24 points (60\% or less).

\section{Content validity}

For tools validation the data were ascertained by a group of five experts, from faculty staff, urology consultant, and nursing supervisor in the urology unit.

Pilot study:

A pilot study was conducted on $10 \%$ (5 patients) of subjects to test the applicability and feasibility of the study tools .obtained results was used as a guide to reconstruct the changes needed in the data collection tools and it was excluded from the total study sample

\section{Reliability}

The tool was modified accordingly Gronpach Alpha,(1951) coefficient test was used to ascertain the ratability of the tool $(\mathrm{r}=0.087)$.

\section{Field work:}

- Official permissions to conduct the study were obtained from the directors of EL Fayoum University, and director of National Cancer Institute, Cairo University before the study was conducted.

- For the purpose of assessment of the patients knowledge about urinary diversion review of current and past available literature and theoretical knowledge were done, using books articles and magazines to develop the tools for data collection.

- Data collection started and it took 6 months (from May to October 2015).

- The researcher interviewed the study sample individually to explain the purpose of the study and obtain the informed consent.

- As research ethics the researchers assure anonymity and confidentiality of patient data. Patients were informed that they are allowed to choose to participate or not in the study and that they have the right to withdraw from the study at any time throughout the interventions.

- The patient filled in the structured questionnaire related to their demographic data which took from five to ten minutes. The questionnaire was filled by the investigator in the out patient clinic.

- Then, the investigator started to assess the patient's knowledge and self care practices regarding to urinary diversion using prepared pre test in the form of the questionnaire.

- The average time consumed in answering the knowledge and self care practices questionnaire about thirty mints duration, (the checklist filled by investigator).

- The investigators started apply Orem theory guideline after finishing the pre test in the form of the questionnaire.

\section{Program construction:}

The Orem's guideline was constructed on four phases, assessment, planning followed by implementation and evaluation. Orem's (1985) general theory is comprised of three interrelated theory: theory of self-care; theory of self-care deficit; and theory of nursing systems. The theories are linked by presuppositions or assumptions. The theme of the self-care theory is that the individuals have the ability to care for themselves and their dependents. In the self care deficit theory, which Orem considers the care of her general theory, the central theme is that there are times when limitations occur in an individual's ability for self-care. These limitations, or therapeutic self-care demands, that establish the need for nursing. Nursing systems is Orem's third theory. It is theory that defines a person's need for nursing. The nurse determines that a deficit exists between the abilities and demands placed on a patient and together with the patient develops a plan of care to meet the patient's need.

\section{Assessment phase:}

The educational program was designed by the researcher, based on the results of assessment (pre test and using the interviewing questionnaire).

\section{Planning of the educational program:}

This phase included analysis of the pre-test findings; the researcher designed the educational section's content according to the patients needs. Detected needs, requirements and deficiencies were translated into the aim and objectives of the educational program sections in the form of guideline booklets. The guideline booklet included knowledge and self care practices about urinary diversion, regarding anatomy \&physiology of the urinary system, radical cystectomy (as definition, , types, indications, complications), uro-stomy definition, indication, and its types, preoperative instructions as fasting ,bowel preparation, skin preparation, connected tube. As well post-operative instructions as breathing exercise, leg and foot exercise, early ambulation, diet, coping, sexual relations, bathing, returning to work, and pregnancy.

\section{Objectives of the guideline:}

The guidelines booklets contain three sections each section had intermediate objective, content and evaluation through asking questions to be answered by the patient at the end of the section. The researcher met 
the patient according to time schedule in the morning shift two days /week to discuss with them, if there was any difficulty or explanation, after all section discussed, the evaluation phase started. If the patients answer all questions correctly then move to the second section.

\section{$>$ Section one:}

Intermidiatte objective: Acquire basic knowledge about urinary diversion:

Content:

- Concept of radical cystectomy.

- Mention the types \& indications of cystectomy.

- Identify the complications of cystectomy.

- Identify definition, types, indications \& complications of uro-ostomy.

$>$ Section two:

Intermediate objective: Acquire basic preoperative\& postoperative instructions:

Content:

- Explain the preoperative instructions as fasting, bowel preparation, and skin preparation, connected tube.

- Identify the importance of compliance with treatment regimens.

- post-operative instructions as breathing exercise, leg and foot exercise, early ambulation, diet, coping, sexual relations, bathing, returning to work, and pregnancy.

Section three:

Intermediate objective: Acquire basic self care practices regarding uro-ostomy:

\section{Content:}

This part concern with self-care practices regarding to uro-stomy with its subtype care, changing pouching system, empting the pouch \& Change the flange.

\section{Implementation phase:}

A. A study group:

A guideline was designed based on analysis of the collected data. The objective of the guideline was guided by the previously determined patients' educational needs in order to improve patient knowledge and self care practices regarding urinary diversion. The application of orem's guidelines were carried at the previously mentioned setting in a special room for each section contained (3-5) patients in the study group in 3 separate main sections for all contents at morning shift two days /weeks. Every section discusses and answers questions to move to the second section. Arabic language was used as real situation modified lecture, demonstration and re-demonstration an instructional media was used including booklet in Arabic language and audiovisual material.

\section{B. Control group:}

The control group will receive only the routine care such as physical examination, laboratory investigation and routine pre \& post operative nursing care.

\section{Evaluation phase}

Though out these phases the researchers was emphasize on evaluating the effect application of self care Orem theory guideline on elderly suffering from urinary diversion, before discharge from hospital, and through the follow up period after 1 month , and 3 months post discharge for both groups through the difference between the control and study groups.

\section{Limitations of the study:}

Some patients withdraw from the study during the interventions and in the follow up phase.

\section{Statistical Analysis:}

The collected data were analyzed and presented in tables, graphs with the suitable statistical tests to identify the significance of results. All data were stratified according to urinary diversion with uni-variate ANOVA analyses (all diversions) and with unpaired sample T tests. Statistical significance was achieved if $p$ was <0.05. All reported p-values were two-sides. All data were recorded, collected and analyzed by using Statistical Package for the Social Sciences 18.0 for Microsoft (SPSS). Statistical analysis with numerical data was expressed as means \pm standard deviations (SD). Patient groups were compared according to the interventions. Cochran's Q test was used to compare between correct responses, satisfactory levels pre-, post as well as at follow-up periods. Repeated measures ANOVA test was used to compare between mean scores in the two groups as well as to study the changes by time within each group. Bonferroni's test was used for pair-wise comparisons when ANOVA test is significant. All statistical tests were two-tailed, and $\mathrm{P}<0.05$ was considered as significant. Multivariate logistic regression analysis was done to account for confounding factors. The significance level was set at $\mathrm{P} \leq 0.05$. Statistical analysis was performed.

\section{Results}


Table (1): Distribution of the studied sample (study and control group) according to their socio-demographic characteristics.

\begin{tabular}{|c|c|c|c|c|}
\hline Socio-demographic characteristics & Study group $(n=25)$ & Control group $(n=25)$ & $x^{2}$ & $P$-value \\
\hline $\begin{array}{l}\text { Age (Years) } \\
\text { Mean } \pm \text { SD }\end{array}$ & $63.5 \pm 7.6$ & $63.6 \pm 8.3$ & $0.044^{\circ}$ & 0.964 \\
\hline $\begin{array}{l}\text { Gender (n, \%) } \\
\text { Male } \\
\text { Female }\end{array}$ & $\begin{array}{l}20(64.0) \\
5(36.0) \\
\end{array}$ & $\begin{array}{l}19(78.0) \\
6(22.0) \\
\end{array}$ & 0.362 & 0.495 \\
\hline $\begin{array}{l}\text { Marital status (n, \%) } \\
\text { Married } \\
\text { Divorced } \\
\text { Widowed }\end{array}$ & $\begin{array}{l}20(80.0) \\
3(12.0) \\
2(8.0)\end{array}$ & $\begin{array}{l}20(80.0) \\
2(8.0) \\
3(12.0)\end{array}$ & 0.400 & 0.818 \\
\hline $\begin{array}{l}\text { Education (n, \%) } \\
\text { Illiterate } \\
\text { Reads and writes } \\
\text { Secondary level } \\
\end{array}$ & $\begin{array}{l}11(44.0) \\
11(44.0) \\
3(12.0) \\
\end{array}$ & $\begin{array}{l}13(52.0) \\
9(36.0) \\
3(12.0) \\
\end{array}$ & 0.675 & 0.714 \\
\hline $\begin{array}{l}\text { Occupation }(\mathbf{n}, \%) \\
\text { Free work } \\
\text { Employee } \\
\text { Retired } \\
\text { Housewife } \\
\text { Professional work } \\
\end{array}$ & $\begin{array}{l}4(16.0) \\
- \\
8(32.0) \\
5(20.0) \\
8(32.0)\end{array}$ & $\begin{array}{l}0(0.0) \\
- \\
10(40.0) \\
4(16.0) \\
11(44.0)\end{array}$ & 8.905 & 0.064 \\
\hline $\begin{array}{l}\text { Residence (n, \%) } \\
\text { Urban } \\
\text { Rural } \\
\end{array}$ & $\begin{array}{l}9(36.0) \\
16(64.0) \\
\end{array}$ & $\begin{array}{l}12(48.0) \\
13(52.0) \\
\end{array}$ & 2.026 & 0.155 \\
\hline $\begin{array}{l}\text { Income for treatment expenses (n, \%) } \\
\text { Sufficient } \\
\text { Insufficient }\end{array}$ & $\begin{array}{l}0(0.0) \\
25(100.0)\end{array}$ & $\begin{array}{l}9(36.0) \\
16(84.0)\end{array}$ & 20.482 & $<0.001 *$ \\
\hline
\end{tabular}

$\bullet$ Independent t-test

*: Significant at $P \leq 0.05$

Regarding socio demo- graphic characteristics of the study and control groups, table (1) shows that mean age of the study group was $63.5+7.6$, while the mean age of control group was $63.6+8.3$. Regarding patient's gender, it was found that, $64 \%$ of the study group and $78 \%$ of the control group were males. As regards their marital status the $80 \%$ of the study and control groups were married. In relation to educational level, $44 \%$ of the study group and $52 \%$ of control group were illiterate. As well as, this table shows that (32\% and $44 \%$ respectively) of the study group and control groups were have professional work Meanwhile, $64 \%$ of the study group and 52\% of the control groups resided in rural areas. Regarding to their income for treatment $100 \%$ of the study group and $84 \%$ of the control group had insufficient income for treatment.

\section{Past and present medical history}

Table (2): Statistical difference between past and present medical history findings in the two groups

\begin{tabular}{|c|c|c|c|c|}
\hline Past and present medical history & Study group $(\mathrm{n}=25)$ & Control group $(\mathrm{n}=25)$ & $x^{2}$ & $P$-value \\
\hline Family member with cancer & $4(16.0)$ & $5(20.0)$ & 0.638 & 0.424 \\
\hline Previous operation & $12(48.0)$ & $7(28.0)$ & 6.112 & $0.013^{*}$ \\
\hline $\begin{array}{ll}\text { Type of operation } \\
-\quad \text { Appendectomy } \\
\text { - } & \text { Hemorrhoids } \\
\text { - } & \text { Cholecystectomy } \\
\text { - } & \text { Tumor removal (other site) }\end{array}$ & $\begin{array}{l}7(28.0) \\
7(28.0) \\
6(24.0) \\
5(20.0)\end{array}$ & $\begin{array}{l}2(15.4) \\
4(30.8) \\
1(7.7) \\
6(46.2)\end{array}$ & 3.853 & 0.277 \\
\hline Positive smoking & $15(30.0)$ & $8(32.0)$ & 0.047 & 0.829 \\
\hline Negative smoking & $7(28.0)$ & $4(32.0)$ & 1.507 & 0.220 \\
\hline $\begin{array}{lll}\begin{array}{l}\text { Awareness } \\
\text { diagnosis }\end{array} & \text { about } & \text { his/her } \\
\end{array}$ & $25(100.0)$ & $25(100.0)$ & $N C+$ & $N C+$ \\
\hline $\begin{array}{ll}\text { Discovery of disease } \\
\text { - } & \text { Through symptoms } \\
\text { - } & \text { Accidentally } \\
\end{array}$ & $\begin{array}{l}25(100.0) \\
0(0.0)\end{array}$ & $\begin{array}{l}25(100.0) \\
0(0.0)\end{array}$ & $N C+$ & $\mathrm{NC}+$ \\
\hline $\begin{array}{l}\text { Complaint on admission } \\
\text { - } \\
\text { Blood in urine and pain when } \\
\text { urinating } \\
\text { Abdominal and lower back } \\
\text { pain } \\
\text { - Weight loss and fatigue }\end{array}$ & $\begin{array}{l}25(100.0) \\
7(28.0) \\
3(12.0)\end{array}$ & $\begin{array}{l}25(100.0) \\
6(24.0) \\
3(12.0)\end{array}$ & $N C+$ & $N C+$ \\
\hline
\end{tabular}

*: Significant at $P \leq 0.05, N C^{\dagger}:$ Not Computed because the variable is constant 
Concerning clinical data of the study and control groups, table (2) shows that $16 \%$ of patients in the study and $20 \%$ of patients in the control groups had family member with cancer, meanwhile, the results reflect that there were no family member have had similar problem in both study and control group. Also, the table shows that $48 \%$ of the study group and $28 \%$ of the control group had previous operation. As regards smoking $30 \%$ of patients in the study and $32 \%$ in control groups were smoking, while, $25 \%$ of study group and $32 \%$ of control group exposed to passive smoking. In relation to discovery of disease $100 \%$ of the study and control group were discover disease through symptoms. As regards complaint on admission all patients in the study and control groups $100 \%$ had blood in urine and pain when urinating. There was no significant difference between the two groups regarding all their clinical data except previous operation where $\mathrm{P}>0.5$.

According to the research hypothesis: Application of self care guidelines will have a positive effect on knowledge and practical skills for elderly patients suffering from urinary diversion (table $3,4 \& 5$ ) and (figure 1 \& 2)

Table (3): Statistical differences between mean knowledge scores in the two groups as well as the changes within each group.

\begin{tabular}{|c|c|c|c|c|c|c|}
\hline \multirow[t]{2}{*}{ Time } & \multicolumn{2}{|c|}{$\begin{array}{l}\text { Study group } \\
(\mathrm{n}=25)\end{array}$} & \multicolumn{2}{|c|}{ Control group $(n=25)$} & \multirow[t]{2}{*}{$f$-value } & \multirow[t]{2}{*}{$\begin{array}{l}P \text {-value } \\
\text { (Between groups) }\end{array}$} \\
\hline & Mean & SD & Mean & SD & & \\
\hline Pre & 2.0 & 0.0 & 1.9 & 0.3 & 2.682 & 0.056 \\
\hline Post & 20.9 & 4.3 & 4.3 & 1.0 & 705.363 & $<0.001^{*}$ \\
\hline 1 month & 19.9 & 4.0 & 8.2 & 2.7 & 295.933 & $<0.001^{*}$ \\
\hline 3 months & 19.7 & 3.7 & 8.9 & 3.5 & 234.276 & $<0.001^{*}$ \\
\hline$f$-value & \multicolumn{2}{|c|}{679.690} & \multicolumn{2}{|l|}{75.715} & & \\
\hline $\begin{array}{l}P \text {-value } \\
\text { (Within group) }\end{array}$ & \multicolumn{2}{|c|}{$<0.001 *$} & \multicolumn{2}{|l|}{$<0.001 *$} & & \\
\hline
\end{tabular}

*: Significant at $P \leq 0.05$, Different superscripts in the same column are statistically significantly different

Table (3) reveals that there were statistically significant difference between the mean and standard deviation regarding patients knowledge about urinary diversion and stoma care in study and control groups at post and follow up of educational guidelines implementation at $\mathrm{p}<0.001$.

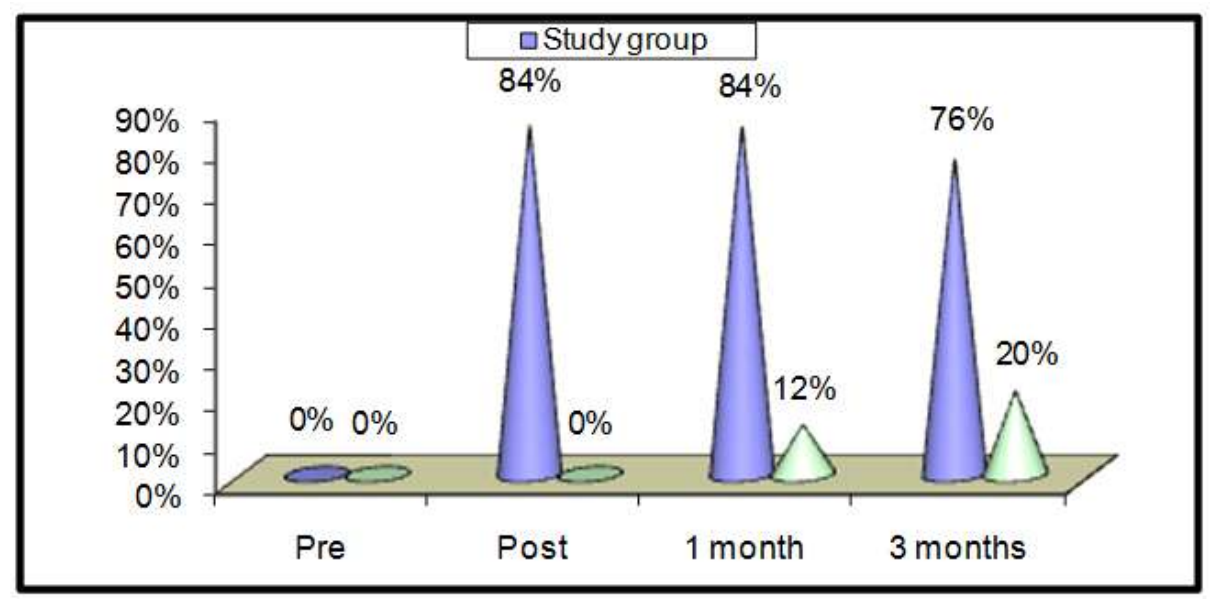

Figure (1): statistical differences between levels of satisfactory knowledge in the two groups

Figure (1) shows that there were unsatisfactory knowledge about urinary diversion and stoma care for both study and control group pre application of guideline improved to (84\%, 84\% \& $76 \%$ respectively ) among study group post, 1 month \& 3month after application of guideline. there were highly statistically significant difference between study group and control group regarding their knowledge about urinary diversion and stoma care at post and follow up of educational guidelines implementation where $\mathrm{p}<0.001$.

Table (4): statistical differences between mean self care practice scores according to orem's theory in the two groups .

\begin{tabular}{|l|l|l|l|l|l|l|}
\hline \multirow{2}{*}{ Time } & \multicolumn{2}{|l|}{$\begin{array}{l}\text { Study group } \\
(\mathbf{n = 2 5})\end{array}$} & \multicolumn{2}{l|}{ Control group $(\mathbf{n = 2 5})$} & \multirow{2}{*}{$\boldsymbol{f}$-value } & $\begin{array}{l}\boldsymbol{P} \text {-value } \\
\text { (Between groups) }\end{array}$ \\
\cline { 2 - 7 } & Mean & SD & Mean & SD & & \\
\hline Pre & 0.0 & 0.0 & 0.0 & 0.0 & $\mathrm{NC}^{\dagger}$ & $\mathrm{NC}^{\dagger}$ \\
\hline Post & 14.7 & 3.5 & 0.5 & 0.1 & 121.358 & $<0.001^{*}$ \\
\hline 1 month & 15.9 & 4.6 & 6.8 & 1.9 & 70.506 & $<0.001^{*}$ \\
\hline 3 months & 16.5 & 5.5 & 6.9 & 2.0 & 77.704 & $<0.001^{*}$ \\
\hline
\end{tabular}


Application of Self Care Orem's Theory Guideline on Elderly Suffering From Urinary Diversion

\begin{tabular}{|c|c|c|}
\hline$f$-value & 96.000 & 96.000 \\
\hline $\begin{array}{l}P \text {-value } \\
\text { (Within group) }\end{array}$ & $<0.001^{*}$ & $<0.001^{*}$ \\
\hline
\end{tabular}

*: Significant at $P \leq 0.05-N C^{\dagger}:$ Not Computed because the variable is constant

Table (4) shows that there were no statistically significant differences between the mean and standard deviation regarding self-care practice in both study and control groups pre-implementation of self care guidelines at $\mathrm{P}>0.05$. while ,there was highly statistically significant difference between them at post and follow up the implementation of self care guidelines where $\mathrm{p}$ value $<0.001$.

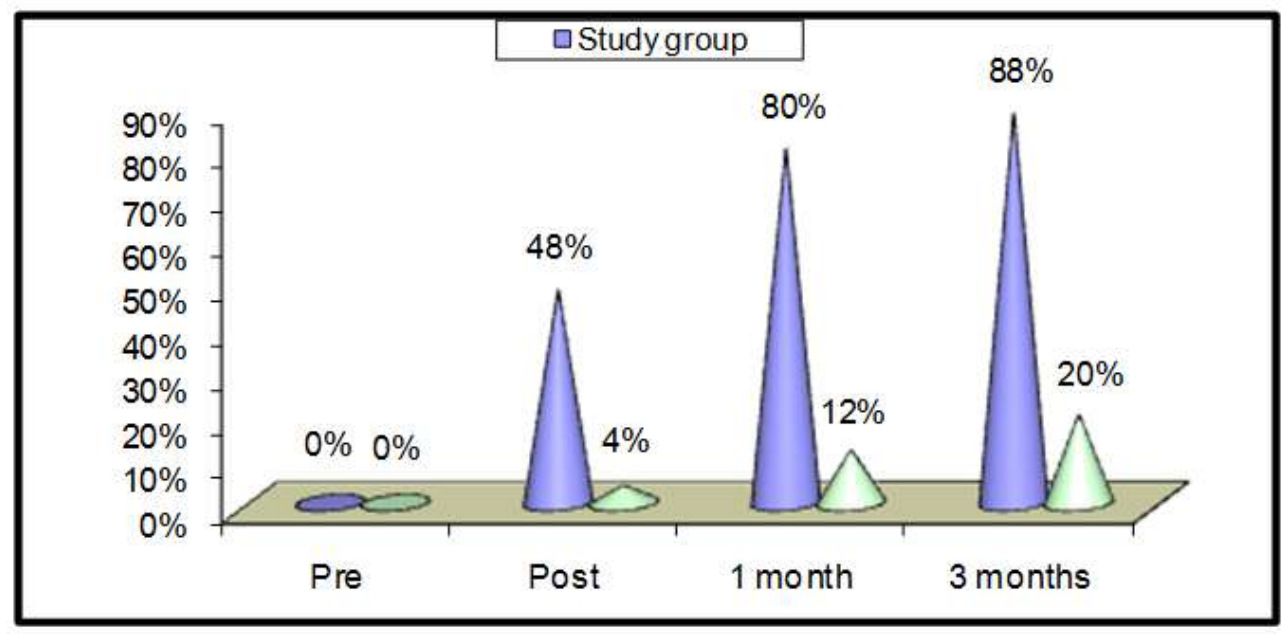

Figure (2): Statistical differences between mean satisfactory self care practice scores according to Orem's theory in the two groups.

Figure (2) indicates that there were unsatisfactory self care practice about urinary diversion and stoma care for both study and control group pre application of Orem's guideline improved to (48\%, 80\& 88\% respectively ) among study group post, 1 month \& 3month after application of Orem's guideline. Also, there were highly statistically significant differences between the study group and control group regarding their total level of self care practice about stoma care at post and follow up phase of the application of Orem's self-care guidelines instruction where $\mathrm{p}$ value $<0.001$.

Table (5): Results of Cronbach's alpha reliability coefficient for knowledge and Orem's self care practice scale.

\begin{tabular}{|l|l|l|l|}
\hline Items & No. of variables & Cronbach's Alpha & $\boldsymbol{P}$-value \\
\hline Knowledge about total cystectomy and urinary division & 8 & 0.718 & $<0.001^{*}$ \\
\hline knowledge about stoma & 18 & 0.702 & $<0.001^{*}$ \\
\hline Orem's self care practice Scale & 14 & 0.824 & $<0.001^{*}$ \\
\hline
\end{tabular}

Table(5) shows that, alpha Cronbach for all items of knowledge were (0.718 and 0.702). The table also shows that, alpha Cronbach for Orem's self care practice Scale were (0.824). Which indicate high reliability of the used tool with statistically significant difference $<0.001$.

\section{Discussion}

According to Socio-demographic characteristic of the study the results revealed that the total number of the participant was 50 patients, half of them were study group and the other half was control group. Regarding the gender it was found that about two thirds of the study group and more than three quarter of the control group were males' .This supporting the finding by Abyed, (2012) in office screening for age related to prostatic and bladder cancer, stated that each year about 20,000 male cases which is more than female complaining of cancer bladder. Also Beaver and Man, (2011) in his study about technology of urinary diversion in America, stated that men have slightly higher incidence of developing urinary diversion surgery than women due to prostatic and bladder cancer.

Regarding to the marital statues the majority of study and control group were married, which is agreed with a similar finding was reported by El-Ganzoury (2012) in his master thesis in assessment of psychological aspects of urology patients mentioned that there were increase in percentage of urinary diversion surgery among married patient and decrease in the percentage of urinary diversion surgery of single, divorced and widowed patients. The present study showed that, about half of the study control and group were educated. From the point of view of the researchers this result may be due to low level of education in Egypt especially in rural areas, as it was reported 
that literacy level among the older adult group was high. The result of the present study revealed that, about one third of them had a professional work, this finding is contradicting with Davies (2011), in his study about promoting healthy aging, who reported that working was found in a high proportion among patients undergoing to urinary diversion surgery. Also, from the point of view of the researchers this results could be because of the majority of the sample was male and they need to work to earn money for their family.Regarding to residence about two thirds of the study group and half of the control group from rural this result may be due to poor knowledge and hygiene among people residence rural area.

Concerning the income, the present study reported that the entire study group and the majority of the control group had not enough incomes for their treatment. From the point of view of the researchers, that working after a life crisis is concerned with the person's ability and capacity to perform tasks which enable them to be productive and maintain a satisfactory life. From the other hand the cost for treatment and cost of surgery leads to imbalance between daily continuing needs and restricted income or insufficient income. According to Past and Present medical history, the finding showed that most of the patient included in both control \& study group had family history of cancer or one of their family at least had cancer, this finding is agreed with Chalasan et al., (2012) in his study in the Canadian bladder cancer stated that most of patients with bladder cancer and undergoing to cystectomy had a positive family history of cancers, with a percentage of $50 \%$, which is supported by Gills (2013) in his education for advanced practice nursing mentioned that about half of the general population receive chemotherapy or radiotherapy had a positive history of cancer and that number increase by $20 \%$. The results revealed that about half of the study group and more than one quarter of control group had previous operation. It also found that one quarter of the study group had appendectomy, hemorrhoids, cholecystectomy and tumor removal before urinary diversion operation. In the same line (yang, et al., 2014) in their research about patients with urinary diversion, there found that $78 \%$ of patients had previous operation while 71.3 had appendectomy. The results were the same line with the Meta analysis assessing the prevalence of cholecystectomy $54.9 \%$ range: $20 \%-89 \%$ and tumor removal $(99.69 \%$ range: $20 \%-89.13 \%)$ in chinese cancer adults. The result of the present study reported that about one third of study group were positive smoking, while about one quarter of them exposed to negative smoking. This result is incongruence with Mohiee-Eldeen (2013) in his study about social and psychological rehabilitation for oncology reported that the majority of cancer's patients had a long duration of smoking (5-10 years).Also Gance-Cleveland (2014) in his qualitative evaluation of geriatric group mentioned that positive smoker were at high risk for cancer.

The study also emphasized that all patient in the study\& control group were discover their disease through symptoms as blood in urine, pain when urinating, In same line with (Vindlhy, et al 2016) in their study about outcome of quality of life among patients with urinary diversions, it estimated 200 patient half of them study group\& the other half control group. The data were collected from record of follow up of patient's pre \& post-surgery. Follow up done through physical visits and phone call. They found that the majority of patients (80\%) of the study group and control group discover their disease through symptoms but only $30 \%$ of them discovered their disease accidently.

\section{According to the research hypothesis: Application of self care guidelines will have a positive effect on} knowledge and practical skills for elderly patients suffering from urinary diversion

Regarding to levels of knowledge in the two groups the results reveals that there were statistically significant difference between the mean and standard deviation regarding patients' knowledge about urinary diversion and stoma care in study and control groups at post and follows up of educational guidelines implementation. Hautmann, (2014) in his study at London, stated that level of knowledge may be measured through pre, post and follow up in clinical practice for several reasons: to assess the impact of current medical or surgical intervention program on level of knowledge, to assess the relationship between level of knowledge and prognosis of intervention program or health outcomes. Finally, there was statistically significance relation between levels of knowledge of patient undergoing to urinary diversion and medical or surgical intervention program. In the same line Hassan, ( 2013) in his study at Banha university mentioned that self-care learning package have positive effect on quality of life for patient with different types of urinary diversion and the main score of knowledge and practice improved significantly after application of self-care learning package.

The results also demonstrates that there were unsatisfactory knowledge about urinary diversion and stoma care for both study and control group pre application of guideline and it was improved among study group in post and follow up phase after application of guideline. This was agreement with study conducted by Karchmer, (2011) about the impact of educational program for patient with cancer bladder \& urinary diversion , who found that the majority of the study group had unsatisfactory knowledge before implementing the educational intervention, meanwhile this finding was disagree with Rosediani et al., (2016) in study about selfcare practice on patient undergoing urinary diversion who found that about half of the study group had satisfactory knowledge about urinary diversion. From the view of the researchers most of patients nowadays go to search in social media\& reading about their health problems before going to do any surgical procedure to 
improve their knowledge \& feel more comfortable to minimize their stress but in our study the sample was elderly patient and half of them residence in rural area that lead to poor dealing with new technology.

Concerning to self care practice scores according to Orem's theory in the two groups the results shows that there were no statistically significant differences between the mean and standard deviation regarding selfcare practice in both study and control groups pre-application of self care guidelines and there was highly statistically significant difference between them at post and follow up the application of self care guidelines. This finding in agreement with Stephen et al., (2014) in a study was done with the objective of assessing the present knowledge, self care practice and attitude of the urinary diversion affected person in rural setting. In this study cross sectional survey was conducted among 100 patients study group and 100 patients control groups, which showed that about $32 \%$ of control group and $37 \%$ of the study group were aware of the color of stoma and how to clean it. Regarding control of the urine out the whole, direction of cleaning the stoma were known to $55 \%$ of the control group and $73 \%$ of the study group. As well $84 \%$ of the study group\& $64 \%$ of the control group knows about the precautions that must followed by the patient during travel, signs should go to the doctor if seen and the food that leads to a change of the smell of urine. Also about $90 \%$ of the study group and $82 \%$ of the control group stated the activity should be avoided after the operation.

The results also indicates that there were unsatisfactory self care practice about urinary diversion and stoma care for both study and control group pre application of Orem's guideline and it was improved among study group during post and follow up phase after application of Orem's guideline. In the same line Shah, (2015) in his study in California pointed that most of patient undergoing urinary diversion had unsatisfactory self care practical skills, this due to patients are ideally admitted to hospital 1-2 days before surgery. During this time information given prior to admission should be reviewed and repeated. The health care professional must be flexible \& able to adapt variety of educational strategies to teach patients self care practical skills. When an individual has begun to acquire some skills, negative feedback may be useful if used appropriately as it helps the learner to establish areas of strength $\&$ weakness on discharge patient are at the "organizing phase" of learning-that is to say that are competent at a skill such as catheterization, but have not yet achieved a level of confidence. It is there for vital that patient had continued support at home from an appropriate health care professional to enable them to move to the "perfecting phase" of learning and satisfactory self care practical skills.According to Cronbach's alpha reliability coefficient for knowledge and self care practice the results indicated high reliability of the used tool with statistically significant difference .This finding was in agreement with (Harby, 2010) in his cross section study that reveled inconsistency and deficiency in knowledge, attitude and self care practice among the patients with urinary diversion. The patient had adequate level of knowledge about urinary diversion after health professional education and training, but their attitude toward the disease and their self care practices was not adequately favorable.From the present study it can summarized that patient education begins before surgery and continues after hospital discharge until the individual can perform self-care practice to maximum practices ability. The goal of the patient teaching is for the patient to transfer the information presented and the skill practiced to everyday life. Patient education is the single most important action toward independence, confidence\& rehabilitation for the patient. Teaching cannot be left to chance. Teaching cannot be left to chance. Teaching should be approached in an organized manner, underpinned by sound principles of teaching and learning using teaching plans where appropriate to ensure that no vital aspects are omitted.

\section{Conclusion}

Based on the findings and the research hypothesis of the present study, it can be concluded that:

The application of self-care guidelines had statistically significant improvement on knowledge and self care practice for patient with urinary diversion pre, post and follow up program implementation phases as well as compared to control group at $\mathrm{p}<0.05$.

\section{Recommendation}

In the light of the present study findings the main recommendations can be stated as follows:

$>$ Patients with urinary diversion need regular follow up to improve their health and prevent complications.

$>$ Periodic implementation of the designed self care guideline booklets cancer's patients in the clinic, out patients and hospitals when the patient admitted to provide them with the necessary and required knowledge and self care practice about their disease is mandatory.

$>$ Further research is needed to investigate the long term effect of such educational intervention on the health of cancer's patients.

\section{References}

[1]. Siegel R.L., Miller K.D. \& Jemal A., (2015): Cancer statistics, CA Cancer J Clin 65:5-29. doi:10.3322/caac. 21254PubMedCrossRefGoogle Scholar 
[2]. Patel H.D., Ball M.W., Cohen J.E., Kates M., Pierorazio P.M.\& Allaf M.E., (2015): Morbidity of urologic surgical procedures: an analysis of rates, risk factors, and outcomes.Urology85:5525doi:10.1016/j.urology. 2014.11. 034PubMedCross RefGoogle Scholar

[3]. Shabsigh A., Korets R., Vora K.C., Brooks C.M., Cronin A.M. \& Savage C., (2011): Defining early morbidity of radical cystectomy for patients with bladder cancer using a standardized reporting methodology. Eur Urol 55:164-174. doi:10.1016/j.eururo.2008.07.031PubMedCrossRefGoogle Scholar

[4]. Hautmann R.E., Abol-Enein H., Hafez K., Haro I., Mansson W., Mills R.D., Montie J.D., Sagalowsky AI., Stein J.P., Stenzl A., Studer U.E. \& Volkmer B.G., (2013): Urinary diversion. In: World Health Organization (WHO) consensus conference on bladder cancer urinary diversion. Urology 69:17-49

[5]. Shariat S.F. \& Milowsky M.,(2011): Bladder cancer in the elderly. Urol Oncol 27:653667PubMedPubMed CentralCrossRef Google Scholar

[6]. Leveridge M.J., Siemens D.R., Mackillop W.J., Peng Y., Tannock I.F., Berman D.M.\& Booth C.M., (2015):Radical cystectomy and adjuvant chemotherapy for bladder cancer in the elderly: a population-based $\quad$ study. Urology 85:791-798. doi:10.1016/j.urology.2014.12.027PubMedCrossRefGoogle Scholar

[7]. Garde H., Ciappara M., Galante I., Fuentes Ferrer M., Gómez A., Blazquez J., Moreno J.\& (2015): Radical cystectomy in octogenarian patients: a difficult decision to take. Urol Int 94:390-393. doi:10.1159/000371556PubMedCrossRefGoogle Scholar

[8]. Schiffmann J., Gandaglia G., Larcher A., Sun M., Tian Z.\& Shariat S.F., (2014): Contemporary 90-day mortality rates after radical cystectomy in the elderly. Eur J Surg Oncol 40:1738-1745. doi:10.1016/j.ejso.2014.10.004PubMedCrossRefGoogle Scholar

[9]. Gore J.L. \& Litwin M.S., (2012): Urologic Diseases in America Project. Quality of care in bladder cancer: trends in urinary diversion following radical cystectomy. World J Urol27:4550.doi:10.1007/s00345-08-034yPubMedPubMed CentralCrossRef Google Scholar

[10]. Nishikawa M., Miyake H., Yamashita M., Inoue T. \& Fujisawa M., (2014): Long-term changes in renal function outcomes following radical cystectomy and urinary diversion. Int J Clin Oncol 19(6):1105-11111PubMedCrossRefGoogle Scholar

[11]. Leow J.J., Reese S., Trinh Q.D., Bellmunt J., Chung B.I., Kibel A.S. \& Chang S.L., (2015): Impact of surgeon volume on the morbidity and costs of radical cystectomy in the USA: a contemporary population-based analysis. BJU Int 115(5):713-721PubMedCrossRefGoogle Scholar

[12]. Shah S.H., Movassaghi K., Skinner D., Dalag L., Miranda G. \& Cai J., (2015): Ureteroenteric strictures after open radical cystectomy and urinary diversion: The University of Southern California experience. Urology 86:87-91. doi:10.1016/j. urology.2015. 03.014PubMedCrossRefGoogle Scholar

[13]. Orem, D.E., (1985): Nursing: Concepts of practice ( $3^{\text {rd }}$ ed.). New York: Mc Graw -Hill.

[14]. SEER Cancer Statistics Factsheets: Bladder Cancer (2016): National Cancer Institute. Bethesda, MD, http://seer. cancer.gov/statfacts/html/urinb.html.

[15]. Ferlay J., Soerjomataram I., Ervik M., Dikshit R., Eser S., Mathers C., Rebelo M., Parkin D.M., Forman D. \& Bray F., ( 2012 ): v1.1, Cancer Incidence and Mortality Worldwide: IARC CancerBase No. 11 [Internet]. Lyon, France: International Agency for Research on Cancer; 2014. Available from: http://globocan.iarc.fr, accessed on 08/09/2015.

[16]. Black J.M. \& Matassarin-Jacobs E., (2015): (eds.). Medical-Surgical Nursing: Clinical Management for Continuity of Care (5th ed.). Saunders: Philadelphia, 1997, pp. 1582-1595.

[17]. Hassan A.E.,(2013): Effect of Self Care Learning Pakage on the quality of Life for Patient with Urinary Diversion, Banha Universty.

[18]. El-Ganzoury , G.,(2012):Assessment of psychological aspect of urology patients. Master thesis ,Faculty of Medicine, Ain shams University, pp 90-108.

[19]. Abyad, A., (2012):In office screening for age related to prostatic \&bladder cancer,Geriatrics,52,45-54.

[20]. Beaver, K.A. and Man, W.C.,(2011):Overview of technology of urinary diversion.American Journal of occupational therapy.49.913-921.

[21]. Davies N.,(2011):Promoting Healthy aging.The impotance of life style.Nurse Stander, Jan.12-18.25.

[22]. Chalasan V., Kassouf W. \& Chin J.L., (2012): Radical cystectomy for the treatment of T1 bladder cancer: the Canadian Bladder Cancer Network experience. Can Urol Assoc J 5 (2): 83-7, 2011. [PUBMED Abstract]

[23]. Gillis, C.L., (2013): Education for advanced practice nursing. In advanced practice nursing changing roles \& clinical applications. Hickey, J.V., Quimette, R.M., \& Venegoni.S.L. (eds.)., Philadelphia- Raven publishers, pp.22-32. 
[24]. Mohiee Eldeen, E.H., (2013): Social \& psychological rehabilitation for oncology. $1^{\text {st }}$ ed. Introduction for cancer rehabilitation. National Council for control \& treatment of malignant tumor. Cairo. Pp 40-59.

[25]. Gance-Cleveland B., (2014): Qualitative evaluation of a geriatric group for adolescents with an smoker parents nurg Res 53(6):379-358.

[26]. Stephen T., Selvary I. \& Parameswari P.J., (2014): Assessment of knowledge, attitude and practice about urinary diversion among patients \& their families in a rural community in Tamil Nadu. Indian J.Lepr. 2014 Jan-Mar, 86(1):7-14.

[27]. Harby S.A., (2010): KAP regarding urinary diversion. A cross section study: Oman J Urology. May; 3(2):60-5.

[28]. Hautmann R.E., (2011): Ileal bladder substitute urology A 47(1): 33-34,36-40.

[29]. Vindhya P., Majnge p., \& Chapa J.B., (2016): Outcome and quality of life among patients who underwent it at CCBRT Hospital Dar Es Salaam 2011/2013.

[30]. Rosediani M. Ranimah Y. \& Harmy M.Y., (2016): Knowledge, attitude \& practice on urinary diversion N.4(1)pp: 89-98.

[31]. Karchmer A.W., (2011): Urinary disease. A text book of urology. Philadelphia, PA: Elsevier Saunders. ( $9^{\text {th }}$ ed. Pp. 1540-1575).

[32]. Annual statistics of the National Cancer Institute (2015)

[33]. Gronbach Alpha, (1951): A tool for assessing the reliability of scales.

[34]. Yang K.J, Baron K.G, Lu B, Naylor E, Wolf L, \& Zee P.C.(2014): Aerobic exercise improves quality of life in older adults with urinary diversion. Sleep Med. ; 11(9): 934- 940. 